* Possui graduação em Direito pela Universidade do Vale do Itajaí (2003), graduação em Filosofia pela Universidade Federal de Santa Catarina (2004) e mestrado em Direito pela Universidade Federal de Santa Catarina (2006). Doutora em Direito pela Universidade Federal de Santa Catarina (2012). Atualmente é professora do Programa de Pós-Graduação em Direito na Universidade de Caxias do Sul (UCS). Email: carolineferri@gmail. com

** Mestranda em Direito pela Universidade de Caxias do Sul (UCS). Membro do Grupo de Pesquisa Direito Ambiental e Ecologia Política na Sociedade de Risco (GPDA-UFSC/CNPq) e do Grupo de Pesquisa Interdisciplinaridade, cidades e desenvolvimento: planejamento sustentável do meio ambiente (UCS/CNPQ). Possui graduação em Direito pela Universidade do Planalto Catarinense UNIPLAC (2011). e-mail: karinegmalinverni@gmail.com

\section{A proteção da água potável enquanto bem comum da humanidade: uma leitura a partir de Vandana Shiva}

\author{
THE PROTECTION OF DRINKING WATER AS A \\ COMMON HUMANITY: A READING FROM VANDANA \\ SHIVA
}

* Caroline Ferri

** Karine Grassi

Resumo: o presente artigo trata da questão da água, considerada esta como bem comum da humanidade e, essencialmente, como direito fundamental Para tanto, parte do que se costuma denominar como "crise da água doce", evidenciada a partir dos anos 90, com inúmeros debates promovidos por instituições de ordem civis e governamentais, quer na esfera interna dos Estados, quer na sua ótica mundial. Os inúmeros fóruns criados acerca do tema tem por intuito a busca de diretrizes, projetos e objetivos de melhoria real para a população, no campo do acesso a água e ao saneamento básico. Nos últimos anos, o debate sobre a água tem incluído em sua pauta a possibilidade de privatização do recurso como uma possível solução para a sua crise. Para tratar do tema, será utilizado o pensamento de Vandana Shiva com relação à água potável, os conflitos regionais e internacionais gerados por sua disputa e o debate cerca da sua privatização.

Palavras-chave: Direito fundamental à água; Privatização; Conflitos por água.

Abstract: the present article deals with the issue of water, considered this as a common good of humanity and essentially as a fundamental right to do so, part of what is usually called as "freshwater crisis", as evidenced from the 90s, with numerous discussions promoted by civil order and government institutions, both internal to the states, either in its global perspective. The numerous forums created on the subject is aimed at the pursuit of policies, projects and goals of real improvement for the population in the area of access to water and sanitation. In recent years, the water debate has included in its agenda the possibility of privatization of the resource as a possible solution to their crisis. To address the issue, the thought of Vandana Shiva with respect to drinking water, regional and international conflicts generated by their dispute and debate about the privatization will be used.

Keywords: Fundamental right to water; Privatization; Conflicts over water. 


\section{INTRODUÇÃO}

A crise ambiental gerou novas orientações para o processo de desenvolvimento econômico e novas demandas para os movimentos sociais (ecologismo/ambientalismo). Esses movimentos, sustenta Leff (2011, p.98-100), apontam para a necessidade de incorporar uma dimensão ambiental ao campo do planejamento econômico, científico, tecnológico e educativo, induzindo a construção de uma nova racionalidade ambiental, questionando comportamentos associados às práticas de consumo derivadas da sociedade pós-industrial, e problematizando as demandas dos movimentos populares, bem como as da classe trabalhadora.

Tais movimentos refletem também a necessidade de uma mudança paradigmática da ação humana no meio natural. Dentre os vários pensadores que tratam do tema, é inegável o papel universal e atual da ecofeminista Vandana Shiva em diversos assuntos relacionados ao meio ambiente, inclusive a proteção e acesso à água doce.

Especificamente no que diz respeito à crise da água doce, a partir do final dos anos 1990, o tema assumiu grande espaço nos debates e na agenda de organizações mundiais. Inúmeros fóruns foram criados na busca de diretrizes, projetos e objetivos de melhoria real para a população, no campo do acesso a água e ao saneamento básico, tendo sido aventada a possibilidade de privatização do recurso como solução para a crise. Empresas fizeram lobby procuraram convencer as comunidades e os governos a adotar este tipo de medida. (BLACK, 2005- p.59)

O recorte principal do presente artigo é o pensamento de Shiva com relação à água potável, os conflitos gerados por sua disputa e, por último, não menos importante, o debate cerca da sua privatização. Parte-se do pressuposto de defesa da água, enquanto bem comum da humanidade e enquanto direito fundamental, através de uma abordagem teórica.

\section{A ÁGUA DOCE NA DISPUTA ENTRE A ESCASSEZ E O LUCRO}

O uso sustentável de um dos recursos mais raros da natureza - note-se que apenas $0,5 \%$ da água disponível na Terra é própria para o consumo humano - gira em torno da questão da necessidade humana de água potável e dos interesses comunitários em um acesso abrangente, de interesses mercantis, e 
até mesmo de conflitos entre países. Indispensável para a qualidade e manutenção de vida do ser humano, a água potável e sua gestão é tema bastante debatido, mas que compreende opiniões divergentes. (BARLOW; CLARKE, 2003, p. 05)

Há crise de água quando uma nação não dispõe de 1.000 metros cúbicos para cada habitante anualmente, na estimativa aceita por Shiva. Números inferiores a esse acarretam prejuízo a saúde da população e ao desenvolvimento econômico de um país. Se cada pessoa possui menos de 500 metros cúbicos anualmente, pode-se entender que a vida da população está em alto risco. (2003, p. 16)

Na Índia, nos anos 1950, haviam disponíveis 3.450 metros cúbicos por pessoa; 40 anos depois, apenas 1.250 metros cúbicos por pessoa. A previsão para 2050 é de 760 mestros cúbicos por pessoa, segundo a autora. O principal fator que contribui para a redução da água na Índia, tal qual em outros países, é a expansão da monocultura de eucalipto, advinda das tecnologias decorrentes da Revolução Verde, que consume muito além da capacidade da natureza em recompor seus reservatórios. Fatores como o desmatamento e a poluição também auxiliam na incapacidade do ambiente em manter e recompor os serviços ambientais, de maneira que sejam contempladas as necessidades de toda a população mundial. (SHIVA, 2003, p. 17)

Outro país afetado pela crise de água é o Himalaia: a aceleração no corte de árvores pra comercialização fez com que o país tivesse de importar alimentos em razão da escassez da água potável, sendo que, ateriormente, a produção alimentícia era comprovadamente autossuficiente. (SHIVA, 2003, p. 17).

Leff (2001, p. 18-25) atenta a respeito dos desvãos do discurso da ordem econômica dominante, que é tão repetido "desenvolvimento sustentável". A apropriação dos recursos naturais e a submissão dos povos às demandas e aos princípios da globalização "simplifica a complexidade dos processos naturais e destrói as identidades culturais para assimilá-las a uma lógica, a uma razão, a uma estratégia de poder para a apropriação da natureza como meio de produção e fonte de riqueza". Dessa forma, com tons de verde, a tendência ainda é a da busca desenfreada e incondicional pelo lucro o que, somado ao consumo desregrado, dá continuidade à exploração dos recursos naturais para além das reais necessidades do ser humano e das capacidades de manutenção de um equilíbrio dinâmico ecossistêmico. 
Na mesma linha de pensamento, Harribey (2014, p. 21) explica que

[...] o valor do estoque de recursos naturais é inestimável em termos econômicos [...], uma vez que tais recursos condicionam a vida da espécie humana. Isso significa que ele não pode ser reduzido a uma categoria econômica. [...] Sem a natureza, o homem não pode produzir nada, nem em termos físicos nem em termos de valor econômico. A atividade econômica insere-se necessariamente em relações sociais e numa biosfera. Não se pode dispensar a natureza para produzir coletivamente valor de uso e não se pode substituí-la indefinidamente por artefatos.

O meio ambiente foi, por muito tempo, negligenciado nas estatísticas econômicas por ser considerado inesgotável. Agora que este se encontra num estado alarmante de degradação, existe a clara pressão - ou mesmo tendência - de valorar a natureza enquanto mercadoria. (HARRIBEY, 2014, p. 21) Existem fortes propostas de incorporação de um preço de mercado para alguns recursos da natureza. Especificamente com relação à água, a nova ideia que se instaura e se conslida é a de que "um bem que era abundante e gratuito e passa a ser escasso deve ser internalizado à contabilidade econômica" (CAUBET, 2004, p. 36). A solução, deste ponto de vista, seria atribuir à água um valor. Entretanto, alerta Caubet, essa concepção economicista não considera as funções sociais e ambientais em toda sua importância e amplitude, e não pode ser compatibilizada com a preservação da natureza para as futuras gerações.

Shiva (2003, p. 14) desenvolve seu raciocínio acerca da apropriação de recursos naturais baseado na ganância de Estados e empresas, que resulta em conflitos regionais e internacionais, bem como em terrorismo. Para a autora, a defesa do estilo de vida europeu e estadunidense é uma declaração de guerra ao planeta: seu petróleo, sua água, sua biodiversidade. A destruição do planeta é certa com a manutenção de um estilo de vida em que $20 \%$ da população mundial utiliza $80 \%$ dos recursos do planeta, ou seja, nega a $80 \%$ das pessoas sua porção justa de recursos naturais. É inviável a sobrevivência da espécie humana ao privilegiar e proteger a ganância e se a economia, também revistida de cobiça, fixa as regras da vida e da morte.

Para exemplificar, o presidente da Nestlé S.A., uma das maiores redes produtoras de alimentos no mundo, Peter Brabeck-Letmathe, afirma que a privatização da água é o caminho certo para conscientização humana da 
importância desse bem, alegando, ainda, não se tratar de um direito fundamental ${ }^{1}$, e sim de um bem de consumo. Entretanto, atribuir valor de mercado não garante à população do planeta o pleno acesso ao recurso, senão tão somente a geração de lucro. A luta por tal perspectiva constitui uma espécie de terrorismo, conforme assevera Shiva (2003, p. 14):

[...] negar aos pobres o acesso à água ao privatizar a distribuição do líquido ou ao contaminar mananciais e rios também é terrorismo. No contexto ecológico das guerras da água, terrorista não é só aquele que se esconde nas cavernas do Afeganistão. Alguns se ocultam em salas de conjuntos corporativos e atrás das regras do livre comércio da OMC, o Tratado do Livre Comércio da Amáerica do Norte (TLCAN) y da Área de Livre Comércio das Américas (ALCA). Se coultam atrás das condições privatizadoras do FMI e do Banco Mundial. Ao se negar em firmar o protocolo do Kioto, o presidente Bush, está comentendo um ato de teorrismo ecológico contra inúmeras comunidades que poderiam ser extintas da Terra devido o aquecimento global. vida sustentável.

Embora tardio, existe o reconhecimento da água potável e do saneamento básico como direitos fundamentais por parte da ONU, conforme resolução da Assembleia Geral de 28 de julho de 2010. Do documento é possível extrair, como ponto primordial para alcançar os Objetivos de Desenvolvimento do Milênio, a necessidade de disponibilizar recursos financeiros de Estados e organizações internacionais, em especial para os países em desenvolvimento, para falicitar o fornecimento, acesso e a boa qualidade da água para todos².

Os últimos dados fornecidos pela ONU são do ano de 2012 e mostram que $11 \%$ da população mundial (783 milhões de pessoas) continuam sem acesso seguro à sendo que $40 \%$ dessas pessoas vivem na África Subsariana. É evidente queestar abaixo do safety access, neste contexto, significa água contaminada e em quantidade muito abaixo do mínimo necessário para uma vida digna, o que provoca inúmeras doenças, frequentemente fatais, colocando estas pessoas em uma zona cinzenta próxima à mera sobrevivência. As estimativas para 2015 são pessimistas: se tudo correr

\footnotetext{
${ }^{1}$ AGUAS con Nestle. S.i.: Producciones Perras, 2013. Son., color. Legendado. Disponível em: <http://www.youtube.com/watch?v=rOm41F_9ocM>. Acesso em: 17 fev. 2014.

2 ORGANIZAÇÃO DAS NAÇÕES UNIDAS (ONU). General Assembly AG10967. Disponível em: <http://www.un.org/News/Press/docs/2010/ga10967.doc.htm>. Acesso em 15 fev. 2014.
} 
como se espera, 605 milhões de pessoas continuarão sem acesso a fontes seguras de água ${ }^{3}$.

Por outro lado, um aspecto a ser considerado é o desperdício de água potável. Segundo Marussia Whately (2014) ${ }^{4}$, o Brasil - que possui $12 \%$ da água potável da superfície terrestre - e o México são os países que mais desperdiçam água potável:

Um estudo divulgado em novembro passado [2008] pelo Instituto Socioambiental (ISA) lançou luz sobre a situação do abastecimento público e do saneamento básico nas 27 capitais brasileiras. O levantamento revela que $45 \%$ da água retirada dos mananciais das capitais são desperdiçados em vazamentos, submedições e fraudes. A quantidade de água jogada fora é estimada em 6,14 bilhões de litros por dia (o equivalente a 2.457 piscinas olímpicas) e seria suficiente para atender ao consumo diário de 38 milhões de pessoas - isto é, toda a população de um país como a Argentina!

A perda de água no Brasil, resultante de vazamentos e outros fatores, é outro dado preocupante, aponta Whately (2014): a perda nas capitais é suficiente para abastecer 38 milhões de pessoas por dia; a cidade do Rio de Janeiro desperdiça o equivalente à quantidade necessária para abastecer 618 piscinas olímpicas.. Investimentos urbanos contribuiriam para a diminuição da perda de água por vazamentos, porém a autora aponta a ausência de investimentos para tanto, e o descaso do poder público e da parte da parte mais forte da sociedade civil.

Outro aspecto relevante é que a desigualdade no acesso à água potável atinge também países ricos, como é o caso dos Estados Unidos, muito embora a ingestão de água contaminada seja mais comum em países pobres (BARLOW, CLARK, 2003, p. 61). Essa desigualdade se acentua quando a defesa do lucro fica acima dos direitos da população: na seca que ocorreu no México, em 1995, Barlow e Clarke (2003, p. 71) afirmam que o governo deu prioridade no abastecimento de água para grandes indústrias estrangeiras e não para os pequenos agricultures locais. Assim, o papel do Estado, enquanto defensor dos direitos positivados, acaba por curvar-se aos interesses da economia global eparadoxalmente, em nome da lei e da ordem - contribui para que a sociedade permaneça desprotegida.

3 WHATELY, Marussia. Haverá água para todos? Le Monde Diplomatique Brasil. Disponível em: <http://www.diplomatique.org.br/artigo.php?id=107>. Acesso em: 12 fev. 2014.

${ }^{4}$ POUPEAU, Franck. E a água foi privatizada... Le Monde Diplomatique Brasil. Disponível em: <http://www.diplomatique.org.br/acervo.php?id=500\&tipo=acervo>. Acesso em: 14 fev. 14. 
O problema da escassez de água potável, como qualquer outro recurso indíspensável para a sobrevivência humana, acaba por gerar conflitos de ordem local, nacional e internacional. Shiva (2003, p. 9) alerta, sobretudo, para a manipulação de informações: algumas guerras por água potável são vistas como guerras étnicas ou religiosas. Alguns autores afirmam, ainda, a existências de uma crise da água. Além dos impactos na qualidade de vida da população de todo o planeta (com notável desigualdade entre regiões e Estados), observa-se disputas e conflitos, velados ou abertos, entre classes socias, entre comunidades e entre países, ponto este que será aprofundado a seguir. (BARLOW, CLARK, 2003, p. 61)

\section{AS GUERRAS PELA ÁGUA}

Na obra Guerras por água: privatização, contaminação e lucro Shiva apresenta sua análise da crise da água, da desigualdade de acesso, dos conflitos gerados pela escassez e, principalmente, dos direitos comunitários que se insurgem contra o ponto de vista economicista de sua mercantilização.

Partindo da premissa de que existem interesses diversos com relação à utilização da água (água como mercadoria versus água como bem indispensável ao consumo humano), a autora apresenta dois tipos de guerras decorrentes desses interesses: (i) as paradigmáticas - lutas por modos de percepção e vivência com a água e (ii) as tradicionais - aquelas em que o enfretamento é feito por granadas e armas. (SHIVA, 2003, p. 9-10)

Shiva (2003, p. 9-10) assevera haver um choque entre duas culturas, quando exemplifica a questão da água engarafada e da água gratuita nas ruas de Jaipur, cidade indiana: a água gratuita e de qualidade representa a cultura que entende a água por algo sagrado, sendo seu fornecimento é obrigatório para a preservação da vida, enquanto a água engarrafada representa a cultura que a valora como mercadoria e que defende como direitos corpoarativos fundamentais seu comércio e propriedade privada.

Na mesma linha de pensamento, Maggie Black (2005, p. 159-160) esclare:

No había 'guerras por el agua' en el sentido de grandes conflictos, pero sí pequeños enfrentamientos entre las ciudades y el campo, entre la agricultura comercializada a gran escala y la doméstica, entre el agua necesaria para la industria y la natureza, entre contaminadores y ecologistas. Casi todos estos conflictos se desarrollaban entre los señores del agua y los siervos del agua; 
entre os usurpadores estatales o privados de los recursos hídricos y los habituales usuarios, es decir, pescadores, agricultores, gente qye transporta el agua en cubos, personas que pagan bastante más de lo que solían cuando abre el grifo, gente forzada a hacer sus pozos más profundos o a bomber el agua desde un nivel del subsuelo acuífero cada vez más bajo y a un conste energético cada vez mayor. De formas distintas y en contextos diferentes, el água se había convertido en un tema polémico.

As guerras paradigmáticas por água se estabelecem em todas as sociedades, em nível global, entre culturas que "compartilham a ética universal da água como uma necessidade ecológica e que estão em luta com a cultura corporativa da privatização, da ganancia". Trata-se da água enquanto bem comum. Em outras palavras, existe conflito entre diferentes povos, porém a água é considerada bem comum e possui um adversário maior, que é a privatização:

Do lado destas guerras ecológicas e paradigmáticas, são milhões de espécies e pessoas que buscam água sufiente para seu sustento. De outro, se encontram um punhado de corporações globais, predominatemente Suez Lyonnaise des Eaux, Vivendi Envirronment y Bechtel, ajudadas por instituições globais como o Banco Mundial, a Organização Mundial de Comércio (OMT), o Fundo Momentário Internacional (FMI) e os governos do G-7. (SHIVA, 2003, p.10)

Por sua vez, as guerras reais pelo acesso à água são conflitos entre regiões de um mesmo país ou, ainda, entre comunidades, como por exemplo, o estado indiano de Punjabe ou a Palestina: em ambas persistem a violencia política e osconflitos derivados, geralmente, do fato de os recursos hídricos serem escassos. Já entre países, os exemplos são conflitos entre Siria e Turquia, entre Egíto e Etiópia, dentre outros tantos. Assim, as disputas reais estão relacionadas à dificuldade de determinadas comunidades na obtenção de água em regiões onde a disponibilidade é baixa.

Barlow e Clarke (2003, p. 79) apresentam fatores ligados à agricultura que apontom guerras de água entre povos indígenas e agricultores. Um exemplo é a disputa que ocorreu no ano de 2001 nas Cataratas de Klamath, no Estado de Oregon (EUA). Para os autores, esse é um mais um exemplo da extração forçada dos recursos naturais, que coloca em risco ecossistemas e viola direitos dos nativos em busca de maior irrigação nas plantações, um direito que se apresenta como tendencialmente absoluto, enquanto que para a coletividade pouco resta. 
Recentemente, no Brasil, mudanças na legislação florestal é alvo de críticas da comunidade acadêmica e científica [Academia Brasileira de Ciências e Sociedade Brasileira para o Progresso da Ciência (2011)], bem como uma proposta de emenda à Constituição (PEC n. 215/2000), que prevê a alteração na demarcação de terras indígenas, são exemplos claros de fragilização da legislação e da disputada por recursos naturais.

Outro ponto de extrema importância para o pensamento de Shiva é que muitos desses conflitos são reprimidos ou ocultados: alguns governos optam por disfarçá-los por conflitos étinicos ou reliogosos, como é o caso da disputa por terra e água entre palestinos e israelitas. Shiva salienta que é possível promover uma eficaz gestão de águas e pôr fim aos combates:

El ciclo del agua nos conecta a todos, y del agua podemos aprender el camino de la paz y el dendero de la libertad. Podemos aprender a transcender la guerras del agua creadas por la avaricia, el desperdicio y la injusticia, todo lo cual genera escazes en nustro planeta tan pleno de agua. Podemos colaborar con el ciclo de agua prar recuperar su abundancia. Podemos trabajar juntos para crear democracias del agua. Y si forjamos democracia, forjaremos la paz. (SHIVA, 2003, p.15)

Em linhas gerais, muitos fatores contribuem para a indisponibilidade de água em determinados pontos do globo. A questão primordial para seu combate está num projeto de gestão que busque o uso sustentável da água, bem como forneça saneamento básica para toda a população, sem distinção de classe social.

Os conflitos gerados por água refletem a ineficácia de governos na distribuição ou na prioridade em outros investimentos. Não obstanste, entendese que ainda a melhor maneira é a gestão por parte do Estado, enquanto ente responsável pelo bem estar da comunidade. Interesses de ordem econômica tendem à otimização tão somente de lucros e, como analisaremos a seguir, as experiências nesse sentido não resultaram em uma melhor distribuição de água.

\section{ANÁLISE E REFLEXÃO ACERCA DE CASOS ESPECÍFICOS DE PRIVATIZAÇÃO DA ÁGUA NO MUNDO}

Contrário à privatização e à mercantilização da água, João H. F. Pes (2005, p. 27) explica a impossibilidade de definir a água enquanto mercadoria, diferente de outros recursos naturais, como a madeira. Para o autor, é mercadoria 
a matéria-prima que sofre mudanças para o fim de um bem de consumo: uma árvore transformada em um móvel. Por sua vez, mesmo com tratamento químico, a água permanece matéria-prima, pois não se enquadra como resultado do processo de produção, muito embora possa gerar produtos, como a tinta. Muito embora essa afirmação seja bastante plausível, o modelo econômico globalmente dominante já incorporou a água como um produto e vê na sua privatização a possibilidade de grandes ganhos de lucro.

No decorrer da história e em todas as partes do mundo, os direitos sobre a água são criados a partir dos limites dos ecossistemas e das necessidades humanas, explica Shiva (2003, p. 33). Assim, esses direitos são naturais e anteriores à criação do Estado e sua evolução está interligada ao contexto ecológico decorrente da existência humana, isto é, a necessidade humana fez com que regras fossem criadas com relação ao abastecimento de água, porém isso não nega o direito natural de ter acesso ao recurso.

Tal qual os demais direitos naturais, os direitos sobre a água são direitos de usufruto e não de posse, esclarece a autora: o povo tem direito a vida e aos recursos que a sustentam e essa é a razão na qual as leis costumeiras aceitam o direito à água como um social e natural. Entretanto, interesses econômicos buscam a mercantilização da água, a partir do discurso de melhorar a má distribuição por parte do Estado, porém muito autores, de diversas áreas do conhecimento, advertem que o real objetivo é a busca por lucro - o lucro é antiético, neste caso, porque não pode ser conciliado com a ideia da água enquanto direito. Da água não depende apenas a dessedentação, senão também a higiene, a preparação de alimentos, a mera sobrevivência.

Existem, atualmente, duas grandes multinacionais que dominam $40 \%$ desse setor de mercado: a Vivendi-Générale des Eaux e a Suez-Lyonnaise des Eaux, ambas francesas, com atividade em 100 e 130 países $^{5}$ (POUPEAU, 2014). Muito embora esses dados estejam um tanto desatualizados (2002), é possível verificar (e o diagnóstico de diversos pesquisadores o comprova) que a tendência privatista da água continua alta. Segundo Poupeau (2014),

[...] no "mercado da água", os dois gigantes franceses e suas inúmeras filiais vêm assinando contratos de privatização muito lucrativos há quinze anos. Os sucessos da Suez-Lyonnaise des Eaux (China, Malásia, Itália, Tailândia, República Tcheca, Eslováquia, Austrália, Estados Unidos) não devem fazer esquecer os da Générale des Eaux (hoje, Vivendi), com a qual a Suez-

5 Idem. 
Lyonnaise se associa às vezes, como em Buenos Aires, em 1993. Nos últimos dez anos, a Vivendi instalou-se na Alemanha (Leipzig, Berlim), na República Tcheca (Pilsen), na Coréia (complexo de Daesan), nas Filipinas (Manila), no Cazaquistão (Alma Ata), mas também nos Estados Unidos, com suas filiais Air and Water Technologies e US Filter.

Sobre a privatização, Amir Khair (2012) discorre que, "uma vez privatizada, a empresa estatal foge do controle do Estado e fica livre para praticar a política que mais lhe interessar [...]". Outro aspecto a ser considerado, adverte o autor, é o ganho das empresas: "[...] a sociedade é sacrificada pelo uso abusivo de tarifas [...] que ocorre em sequência à privatização".(KHAIR, 2012) Dessa forma, sugere o autor, que a melhor forma de melhoramento dos serviços é questionar e reavaliar o papel do Estado e também da economia perante à sociedade. Em outros termos, a privatização deve ser evitada, pois não objetiva, como prioridade, a melhoria do serviço prestado à comunidade. $\mathrm{O}$ papel do Estado, enquanto prestador de serviços que contribuam para o bem estar de população deve ser discutido, porém não substituído.

A privatização da empresa municipal Semapa (Servicio Municipal del Agua Potable y Alcantarillado) da cidade de Cochabamba (Bolívia) em 1999, é um dos maiores exemplos de guerras por águas. (SHIVA, 2003, p. 113) Através de recomendação do Banco Mundial, a privatização concedeu à International Water, subsidiária de Bechtel, a prestação dos serviços de saneamento e água potável para a cidade.

Diante da aprovação da Lei n. 2029, em 20 de outubro de 1999 (Ley de Saneamiento y Agua Potable), com previsão de aumento exorbitante dos valores pagos pela população, a sociedade, descontente, criou uma aliança cidadã chamada La Coordinadora de Defensa del Agua y de la Vida que, mediante mobilização de milhões de bolivianos, de diversas partes do país, organizou manifestações com pedidos de revogação da referida lei, comenta Shiva (2003, p. 111). Depois de meses de resistência (censuras, vilência e mortes), a população obteve êxito e o governo revogou a lei, tendo em vista a desistência das empresas privadas 6 .

Shiva (2003, p. 114) salienta que através da atitude dos cidadãos bolivianos ficou claro a possiblidade de impedimento da privatização da água e do saneamento básico, de maneira democrática e refletindo a vontade do povo.

Caso semelhante ao boliviano ocorreu na Argentina em 1997. Os moradores de Tucumán iniciaram desobediência civil, ao recusar o pagamento 
de contas de água, em desfavor de um filial da empresa Vivendi. A recusa explica-se pela precariedade do serviço prestado e por seu aumento em mais de $100 \%$, em comparação com o valor pago quando se tratava de uma empresa estatal. (POUPEAU, 2014)

Entretanto, mesmo com as manifestações da população, o governo apresentou sanções à empresa a partir da descobreta de contaminação na água fornecida para a comunidade. Após ameaças de suspensão dos serviços, a Générale des Eaux propôs renegociação de contrato e, finalmente, retirou-se do papel de fornecedora, não tendo cumprido diversos itens do contrato. A empresa chegou a pleitear indenizações perante o ICSID (International Center for Settlement of Investment Disputes), porém tais ações não lograram êxito. (POUPEAU, 2014)

Com relação à privatização da água, o debate já foi tema do Fórum Mundial da Água, da ONU, em 2000. Barlow e Clarke (2003, p. 95-96) salientam que o título da conferência sugeria a preservação mundial dos recursos hídricos, porém não cumpriu com seus objetivos: com inúmeras "organizações de lobby comercial", os debates ocorreram em torno da problemática de como beneficiar empresas com a venda da água. Afirmam os autores (2003, p 96), que

[...] é verdade que os funcionários da ONU estavam presentes por meio de uma Conferência Ministerial vinculada ao evento, onde foram representados mais de 140 governos. Mas eles não tomavam as decisões. Os principais participantes eram algumas das maiores corporações do mundo - aos autoproclamados salvadores da crise global de água. Eles não somente incluem gigantes globais da água, como a Vivendi e Suez, mas também grandes conglomerados de processamento de alimentos como a Nestlé e a Unilever, os fornecedores de água engarrafada. O debate sobre se a água deveria ser designada uma 'necessidade' ou um 'direito' não foi simplesmente uma questão semântica. Esse debate abordou o núcleo da questão sobre quem deveria ser responsável por assegurar que as pessoas tenha acesso à água - a essência da própria vida. Seria o mercado ou o estado, as corporações ou os governos? O debate não teria ocorrido, com toda certeza, se não fosse pela presença de um pequeno grupo de entidades de sociedades civis. Trabalhando juntos, sob uma bandeira comum que ficou conhecida como o 'Projeto Planeta Azul', os representantes de grupos de interesses ambiental, trabalhista e público, tanto das nações industrializadas quanto das nãoindustrializadas, insistiram para que a água fosse reconhecida como um direito humano universal. 
Assim, o direito humano universal à água resultou da iniciativa popular e de organizações da sociedade civil, uma vez que os interesses ferozmente defendidos pelas empresas visando o lucro em detrimento do adimplemento de diversos direitos estreitamente vinculados. É conveniente ressaltar que o sentido da democracia vai além das eleições para representantes no governo e que as questões ambientais necessitam da participação efetiva da população, pois tratamse de assuntos coletivos de interesses geracionais diversos. Nesse sentido:

A questão ambiental, vista a partir dos interesses dos atores sociais do campo [visa] a um projeto de democracia direta, em relação com a gestão comunitária dos recursos produtivos e à socialização da natureza, aberta a uma diversidade de alternativas ecológicas e culturais. A democracia se redefine, assim, em termos da propriedade, do acesso e da apropriação efetiva dos recursos ambientais e do vínculo social entre os objetivos da sustentabilidade e da igualdade social. O princípio de equidade é proclamado tanto pelo discurso do liberalismo social como pelo discurso do desenvolvimento sustentado. No entanto, as políticas sociais abandonam a participação efetiva da sociedade e a distribuição de oportunidades, de empregos, e da própria riqueza aos resultados das políticas de ajuste estrutural e crescimento econômico. (LEFF, 2006, p. 471).

Shiva (2003, p.33) fixa a globalização e a privatização dos recursos hídricos com principal causa da deterioração de direitos, em razão do controle corporativo de bens coletivos, bem como as necessidades reais, muito além do mercado e do Estado, são deixadas de lado. Vandana Shiva e María Mies (1998, p.13) consideram a existência de muitos vínculos entre a mulher e a natureza. Para estas autoras "a marginalização das mulheres e a destruição da biodiversidade" são oriundos do "modelo patriarcal" e o progresso continua por pressionar os recursos naturais, a biodiversidade. Os direitos das mulheres e o direito ao meio ambiente estão estreitamente relacionados. Por sua vez, a participação feminina nas questões ambientais tem papel fundamental na luta por direitos, e contribuem não apenas com ações particularizadas e de alcance local, senão em autênticas mudanças paradigmáticas na forma de relacionamento entre homens e mulheres, e destes com os ecossistemas e os recursos naturais.

\section{CONSIDERAÇÕES FINAIS}

Muito embora a amplitude de conteúdo e casos concretos, não se pode fixar um planejamento padrão de distribuição de água potável em termos globais. 
É preciso respeitar as necessidades de cada povo, cada região e, principalmente, as condições financeiras da comunidade. Diante da produção deste texto, esclareceu-se que a mercantilização/privatização dos serviços referente à água doce e saneamento básico não logram êxito apenas pelo fato de deslocar-se a propriedade o fornecimento da água da esfera pública para a esfera privada.

Os exemplos apresentados, com base na bibliografia estudada confirmam a premissa de que o principal objetivo implícito nas medidas de privatização é o lucro privado e concentrado em detrimento da realização de um direito humano universal. Alguns serviços pioraram mesmo com o aumento do custo pago pela população, como é o caso da cidade de Tucumán, na Argentina, e as tentativas de privatização seguem um padrão global de avanço das relações capitalistas para esferas que dizem respeito à persecução de direitos humanos, e que tocam muito diretamente os direitos à vida e à dignidade.

Por mais que as prestações de serviços públicos estejam, em determinados casos, em patamares muito abaixo do esperado, verifica-se que, com relação à água, a via pública-estatal (ou coletiva-comunal) constitui um pré-requisito para que a população tenha certo controle de qualidade e possa, se necessário, exigir seu direito pelas vias administrativas ou jurisdicionais. A partir do momento em que o cidadão passa a ser nada além do que um consumidor (no sentido de pagar pelo que consome), é a lógica financeira que dita as regras, os valores e a qualidade do serviço, e se a maior margem de lucro resultar na falta de fornecimento, ou o impedimento fático do acesso a este bem para grande parte da população, regiões, grupos ou classes sociais, o fornecedor não hesitará em fazê-lo, ao abrigo da lei e do contrato.

Outro ponto relevante apresentado pelo presente texto é a tendência de mercantilização dos recursos naturais, antes ignorados nos cálculos econômicos. O pensamento de Shiva contribui neste aspecto, ao sustentar a valorização do ambiente, enquanto bem coletivo e escasso, para além da dimensão meramente mercantil. $\mathrm{O}$ direito humano/fundamental à água potável deve ser garantido e ampliado. Por fim, é através de uma leitura pertinente do papel do Estado - enquanto ente prestador dos serviços e do acesso à água e facilitador de um controle democrático sobre este direito, para além do mero direito ao voto - que se faz possível buscar uma distribuição mais justa, com redução das guerras pela água e com a instituição de uma base mínima para a sobrevivência, a vida digna e a sociabilidade. 


\section{REFERÊNCIAS}

AGUAS con Nestle. S.i.: Producciones Perras, 2013. Son., color. Legendado. Disponível em: <http://www.youtube.com/watch?v=rOm41F _9ocM>. Acesso em: 17 fev. 2014.

BLACK, Maggie. El secuestro del agua: la mala gestión de los recursos hídricos. 1 ed. Traducción Ana Isabel González García. Barcelona: Intermón Oxfan, 2005.

BARLOW, Maude; CLARKE, Tony. Ouro azul: como as grandes comporações estão se apoderando da água doce do nosso planeta. Tradução Natália Coutinho Mira de Assumpção. São Paulo: M. Books, 2003.

BRZEZINSKI, Maria Lúcia Navarro Lins. Água doce no século XXI: serviço público ou mercadoria internacional? São Paulo: Lawbook, 2009.

CAUBET, Christian Guy. A água, a lei, a política... e o meio ambiente? Curitiba: Juruá, 2004.

HARRIBEY. Jean-Marie. Criar riqueza, não valor. Le Monde Diplomatique Brasil. Ano 7, n. 79. Fev. 2014. p. 20.21.

KHAIR, Amir. Privatiza ou estatizar? Le Monde Diplomatique Brasil. Ano 6, n.63. Outubro de 2012.

LEFF, Enrique. Saber ambiental: sustentabilidade, racionalidade, complexidade, poder. Tradução Lúcia Mathilde Endlic Orth. 8 ed. Petrópolis: Vozes, 2011.

. Racionalidade ambiental: a reapropriação social da natureza. Tradução Luís Carlos Cabral. Rio de Janeiro: Civilização Brasileira, 2006.

MIES, María; SHIVA, Vandana. La praxis del ecofeminismo: biotecnologia, consumo, reproducción. Traducción Mireia Bofil y Daniel Aguilar. Barcelona: Icaria Editorial, 1998. 
ORGANIZAÇÃO DAS NAÇÕES UNIDAS (ONU). General Assembly AG10967. Disponível em: <http://www.un.org/News/Press/docs/2010/ ga10967.doc.htm>. Acesso em 15 fev. 2014.

The Millennium Development Goals Report. United Nations: New York, 2012, p. 52. Disponível em: <http://www.un.org/millen niumgoals/pdf/MDG\%20Report\%202012.pdf>. Acesso em: 09 fev. 2014.

PES, João Hélio Ferreira. O Mercosul e as águas: a harmonização, via transfronteiriças do Brasil e Argentina. Santa Maria: UFSM, 2005.

POUPEAU, Franck. E a água foi privatizada... Le Monde Diplomatique Brasil. Disponível em: <http://www.diplomatique.org.br/ acervo.php?id=500\&tipo=acervo $>$. Acesso em: 14 fev. 2014 .

RODRIGUEZ, Arantxa. Las mujeres y el medio ambiente: razones para un feminismo ecologista. In: Cuadernos del Guincho: Espanha, n. 31, 2000, p. 98-104.

SHIVA, Vandana. Las guerras del agua: privatización, contaminación y lucro. 1 ed. México: Siglo XXI, 2003.

WHATELY, Marussia. Haverá água para todos? Le Monde Diplomatique Brasil. Disponível em: <http://www.diplomatique.org.br/artigo.php?id=107>. Acesso em: 12 fev. 2014.

Artigo recebido em: 03/04/2014 Aprovado para publicação em: 07/11/2014

Como citar: FERRI, Caroline. SILVEIRA, Karine Grassi Malinverni da. A proteção da água potável enquanto bem comum da humanidade: uma leitura a partir de Vandana Shiva. Revista do Direito Público. Londrina, v.9, n.3, p.9-24, set./dez.2014. DOI: 10.5433/1980-511X.2014v9n3p9. 